\title{
Korea holds firm to biotech expansion
}

[SEOUL] Despite a struggling economy battered by financial scandals, South Korea still plans almost to double its support for biotechnology next year as part of a programme under which government and industry have promised to invest US $\$ 18$ billion over a 14-year period. But Korean scientists still face obstacles before a strong biotechnology industry can be developed.

The Biotech 2000 programme was set up by the government in 1994 as an offshoot of the Highly Advanced National Project otherwise known as the G-7 project — which aims to catch up with the world's seven leading industrialized countries in a broad spectrum of key technologies (see Nature 354, 177; 1991).

Biotech 2000 aims specifically to catch up in biotechnology by the year 2007, the minister of science and technology, Sook-Il Kwun, said at the opening this month of a conference in Seoul on 'Bioscience Meets Engineering', co-organized by Nature and the Korea Research Institute of Bioscience and Biotechnology (KRIBB).

Almost US $\$ 500$ million has been invested by the government in the first four years of the programme, matched by about $\$ 1$ billion from industry. Next year, the government will increase its budget by 80 per cent to $\$ 312$ million, while industry plans to boost its contribution by 30 per cent to $\$ 470$ million.

Seven ministries are participating in the project. Research focuses on strategic areas that include biomaterials, biomedical engineering, genome analysis, cell culture, breeding of biological resources, food and environmental biotechnology, bioenergy production and basic life science.

KRIBB in Daeduck science city in central Korea is a key player in the project, and funds for basic research are also dispersed to universities through the Korea Science and Engineering Foundation, including its centre-of-excellence programme which provides large amounts of funding to a few select laboratories (see Nature 364, 383; 1993).

About 80 Korean companies are now involved in biotechnology, including large conglomerates such as Samsung and Lucky Goldstar that are more famous for their electronics products. Samsung, for example, has established a biomedical research institute at a new hospital it has built in Seoul, and plans to expand research facilities at the hospital in collaboration with Sung Kyun Kwan

\section{Troubled reactor $w$ ins five-year reprieve}

[токуо] Japan's troubled prototype advanced thermal nuclear reactor, Fugen (pictured right), will continue operating for a further five years out of consideration for its $\mathbf{3 0 0}$ employees and because of its contribution to the local economy. The Science and Technology Agency (STA) has abandoned the idea of closing it down early.

The agency announced last week that Fugen, which comes under the Power Reactor and Nuclear Fuel Corporation (PNC), will continue operating until 2003, two years longer than initially planned. The decision came despite a series of accidents at the site, the most recent in October, when two plant workers were exposed to radiation during a routine inspection.

Fugen, in the reactor-studded Tsuruga City in Fukui Prefecture on the coast of the Sea of Japan, is the only heavy-water reactor among Japan's 50 operating nuclear reactors. The closure decision was made by the STA when a leak of tritium and heavy water in April was left unreported by the PNC for more than 30 hours (see Nature 386,746 ; 1997). Further investigations revealed that there had been 18 unreported cases of tritium leakage since 1992.

The incident followed a series of nuclear accidents and cover-ups by the PNC.

Responding to growing criticism and public discontent about mishandling of nuclear

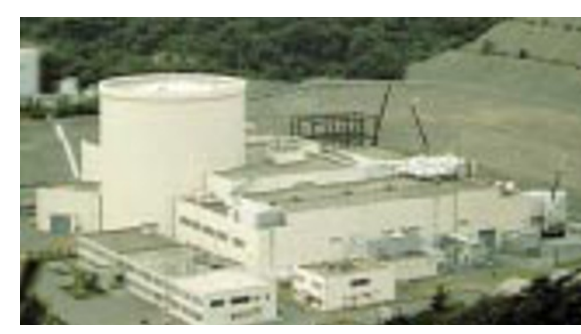

accidents, the STA formed a PNC reform committee to draw up measures for its reorganization.

After the committee's decision to shut the Monju experimental reactor and Fugen, the ruling Liberal Democratic Party's administrative reform council made plans to create a semi-private organization to take over part of PNC's core activities, including the operation of Fugen before closure.

The plan to extend Fugen's operations came after local authorities in Fukui, concerned about the local economy and employment, protested against the early closure. The reactor has been shut since the summer for inspection, and will restart some operations in December.

It is still not known when the new fiveyear term will begin. "It will start some time next year, but it could be as late as next October, when Fugen is handed over to the new controlling body," says one STA official.

Asako Saegusa

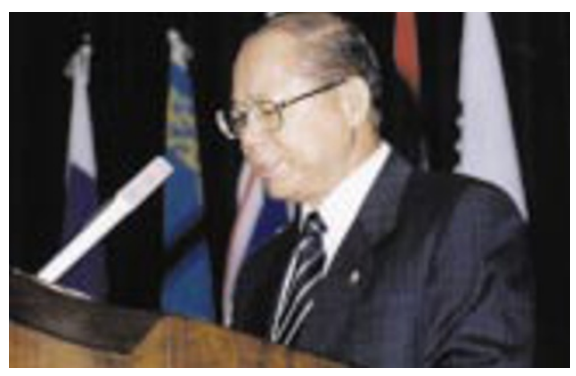

Kwun: ambitious goals for biotechnology.

University, a private university in the outskirts of Seoul where Samsung recently funded the creation of a medical faculty.

But the government is also encouraging small and medium-sized companies to be involved in biotechnology. Some have traditional strengths in food and fermentation.

Korean scientists see big hurdles to overcome to bring biotechnology up to the level of Western countries. For example, although the government is deregulating the financial system to free up more venture capital, the capital available is small compared to the United States, Japan and Europe.

Also, venture capitalists in Korea tend to prefer to invest in areas such as computer software that provide a "quick cash return", Sunyoung Kim of Seoul National University told the conference. Kim has helped his postdoctoral fellows and graduate students to set up a venture business in a corner of his laboratory to develop retroviral vectors for gene therapy, and is turning to companies in neighbouring Asian countries to raise venture capital to compete with the "big boys" in the United States.

Another problem is the lack of a supportive culture in universities. Faculty members of Korea's top universities tend to spend their whole careers in the same department. This, combined with Confucian values that require respect for elders, makes it difficult for young faculty members to develop radical ideas and approaches.

"Living harmoniously is a much more important task [for faculty members] than painfully changing the system, even though that would be good for the university and society in general," says Kim. There is also strong resistance among many university researchers to involvement in business activities, which are considered outside the realm of academic research.

A shortage of people in universities and government with strong backgrounds in biotechnology also hinders development. But growing numbers of young Korean researchers are now returning from the West, introducing new approaches. This leaves Kim and others optimistic about the future of biotechnology in Korea, despite the many problems they face.

DavidSw inbanks 